\title{
SCOPE AND FEATURES OF MUSEUM SETUP TECHNIQUES IN ORAL PATHOLOGY
}

\section{Dr. M. Parasakthi}

Postgraduate Student, Sree Balaji Dental College and Hospital, Chennai

\author{
Article Info: Received 28 September 2020; Accepted 16 November. 2020 \\ DOI: https://doi.org/10.32553/jbpr.v9i5.808 \\ Corresponding author: Dr. M. Parasakthi \\ Conflict of interest statement: No conflict of interest

\section{ABSTRACT:}

The preservation of pathological specimens has become very significant as it is a potential teaching tool and important source of data. Museum has been made compulsory in medical and dental schools by various countries as it is not a mere storage of old and rare specimens, but a vital learning aid in the field of medicine. The procedure of museum setup requires both scientific and technical skills. The term 'Museum technology' together constitutes the method of collection, preservation and storage of specimens. This article aims to review the basics in setting up a museum. Emerging advancements in museum techniques are also highlighted.

Keywords: Museum, mounting of specimens, museum technique, plastination.

\section{INTRODUCTION}

ICOM statutes define museum as 'a non-profit, permanent institution in the service of society and its development, open to the public, which acquires, conserves, researches, communicates and exhibits the tangible and intangible heritage of humanity and its environment for the purposes of education, study and enjoyment ${ }^{[1]}$. A good museum requires proper planning in terms of space, illumination, display shelves, ventilation and location preferably at the entrance ${ }^{[2]}$. Since oral lesions are variable, crafting a museum requires more manpower and flexible material. Contact with tap water may result in haemolysis. Hence specimens should be washed only with saline. ${ }^{[3]}$

\section{Guidelines for setting up of a museum}

The main objective of the museum techniques is to provide a top notch visual revision of teaching and also has the advantage of always being open. ${ }^{[4]}$ The guidelines for setting up of a museum include [5]

- Plan of the museum along with specified timings for the visitors.

- Motto should be added

- Data on total specimens displayed must be kept at the entrance and updated periodically.

- A catalogue or brochure should be provided to the visitors for easy navigation.
- Self-explanatory, labelled museum jars.

- Feedback form or suggestion box.

\section{Basic museum techniques}

Any specimen to be displayed in the museum is handled by the following steps.
1. Reception
2. Preparation
3. Fixation
4. Restoration
5. Preservation
6. Presentation

\section{Reception}

The specimen received in the museum should be recorded in a Reception book and a proper number is provided followed by year. For e.g. 11/2020. This unique number will be written on tie-on type label in indelible ink and it is firmly attached or stitched to the specimen. The reception book must contain all relevant information required about the specimen like clinical, gross and microscopic findings etc.

\section{Preparation of the specimen}

The specimen should be received in fresh condition. It can be obtained either from biopsy or from operation theatre. Cutting of specimen can be done either using brain knife or butcher's knife. The cut surface should be smooth and even by 
using continuous stroke with the long-bladed, sharp knife. Tissue can be taken either from the back of the specimen or from the front with a scalpel. It should be immersed in proper fixative immediately.

\section{Fixation of the specimen}

When a tissue is taken from the body, selfdestruction or autolysis is initiated soon after cell death by the action of intracellular enzymes causing the breakdown of protein and liquefaction of the cell. Fixation prevents autolysis and bacterial decomposition and stabilizes the cellular and tissue constituents. The volume of fixative should be 20 times the volume of specimen ${ }^{[6]}$. Insufficient use of fixation results in cloudiness of the solution. In order to obtain specimen in a good condition, specimen should be suspended in the fixatives. The commonly used fixative is $10 \%$ neutral buffered formalin. Kaiserling method is the most common method used in fixation. Specimens should always be injected with fixatives to ensure adequate fixation. If the specimen contains blood, then it should be washed in water either before or after fixation ${ }^{[7]}$. If the specimen is fresh, it should lie on the thick layer of cotton wool covered by lint.

\section{Restoration}

In order to restore the colour of the specimen, various methods are used. Commonly used method is Kaiserling II method. This method involves removing the specimen, washing it in running water and transferring to $95 \%$ alcohol for 10 minutes to 1 hour depending on the size of the specimen. The specimen is then kept and observed for any change in colour around 1 to $1.5 \mathrm{hrs}$. After this step, the specimen is ready for preservation. If the specimen floats, it should be lightly covered with surgical gauze and the vessel is closed in order to prevent it from evaporation. Pulvertaft in 1936 has described a method of restoring the colour to the tissue by addition of reducing agents to the mounting fluid. Specimens mounted by this technique showed remarkable little fading even after 25 years. Carbon monoxide has also been employed as a colour retaining agent. Schultz introduced the technique, which gives good colour contrast but entails the risks of poisoning and explosion and also colours are unrealistic.

\section{Preservation of the Specimen}

After restoration process gets completed, the specimens are preserved in large rectangular earthenware tanks and mounted. The purpose of mounting of specimen is to protect fragile or coated material during preparation and to obtain perfect edge retention ${ }^{[8]}$.

Procedure

Specimens are prepared by trimming it to the required size and shape such that the specimen fits into the jar. All the unwanted and nonrepresentative tissues are removed by careful dissection. The specimens which will not remain in a natural position by normal mounting methods such as cavities should be filled with arsenious acid gelatine. Regular cuts are given keeping in anatomical position.

\section{Routine mounting procedure}

The mounting procedure for museum includes the following steps ${ }^{[9]}$.

i. Using museum jar or box

ii. Using centre plates

iii. Stitching specimens to the centre plate

iv. Filling and sealing

\section{i. Using museum jar or box:}

Perspex boxes are used almost universally which are available commercially or may be made in the laboratory. The method employed commercially to join the sides is far superior to the cementing process that is done in the laboratory. The specimen should be laid flat on a waterproof bench. The position of the specimen should be made anatomically correct. It is then measured allowing $1 / 2$ inch clearance at the bottom. Depth is measured and approximately $1 / 4$ inch is added for centre plate.

\section{ii. Using centre plates}

Specimens are stitched by using a flat sheet of perspex. Commercial boxes are available with already fitted centre plates. Coloured opaque plates may be used to enhance the colour of the specimen or to attach specimen on both sides.

\section{iii. Stitching specimens to the centre plate}

Proper arrangement of specimen is made and crosses are made on the centre plate with a scribe where stitches are to be placed. With solid specimens, the number of stitches will depend on 
the weight and consistency of the tissue. Stitches must not be placed through pathological lesions. Holes are drilled based on the thread used. If thread is linen, then one hole is drilled. If nylon thread is used, two holes are drilled. Length of linen thread is cut and a small clear glass bead is threaded on and tied at the centre. The centre plate is thoroughly washed in a detergent and dried. The specimen is stitched on by passing first one end of a tie and then the other through the centre plate. The centre plate with specimen is put into the box and marks are made with a grease pencil. If the box is of correct depth, there will be no movement of the specimen ${ }^{[10]}$

\section{iv. Filling and sealing}

When the specimen is in position, museum fluid to which 0.4 percent sodium hydrosulphite has been added is run into within $1 / 2$ inch of the top. Air bubbles trapped between the specimen and centre plate are released with a broad bladed spatula. A hole of $1 / 8$ inch in diameter is drilled in one corner of the lid and the box is wiped dry. After drying the box, perspex cement is applied using a Pasteur pipette. A short perspex rod of $1 / 8$ inch in diameter is tapped lightly into the hole in the lid and the specimen is left for 24-48 hrs to remove residual air bubbles. When the last bubble is removed, the perspex plug is placed and tapped and dried and a small amount of perspex cement is applied. The specimens are then mounted. Glass jars are sealed with an asphaltum- rubber compound.

\section{Presentation}

Museum specimens should be clearly labelled and a catalogue should be employed which allows easy and rapid access. When the specimens are used for examination, it is best to employ a numerical system of labelling. Labels can be of different colour. A good method is a modification of the decimal system where-by the first 2 figures of a four-figure number indicate the type of conditions. The remaining figures divide the subsection and redivide it again. Four, five or six figures may be used for this purpose. By prefixing the number with a letter, the section of the museum is shown. A loose-leaf system is essential to enable the new specimen to be easily listed.
Recent techniques in setting up of a museum.

\section{Plastination}

Plastination is an exclusive way of preservation of biological material with its varied application in numerous schools and research institutes across the globe. It was discovered in

1978 at the University of Heidelberg by Dr. Gunther von Hagens.

\section{Principle}

The principle of plastination is based on the replacement of water and lipids in the specimen by a curable polymer.

The steps involved in plastination procedure are

$>$ Fixation in formalin or Kaiserling solution

$>$ Dehydration in acetone for three changes.

$>$ Defatting in acetone for few hours.

- Forced impregnation in polymers.

$>$ Curing with UV light or other lamps

> Finishing and trimming the flash.

Plastination can be performed by any of the polymers. epoxy, silicone rubber, and polyester. However. polyester is the most preferred one. Each material will produce specimen with appropriate physical characteristics.

The advantages of plastination include simple, inexpensive properties. Disadvantages are that they are time-consuming and technique-sensitive [11]

\section{Virtual museum}

It is an online museum through which a collection of digitally recorded images, sound files, text documents can be accessed by the internet viewers. Though it does not house actual objects, it mimics a museum for those people who cannot visit the actual museum and therefore accessible at any distant site.

\section{Conclusion}

Museums acquire, preserve, interpret and exhibit the tangible and intangible evidence of society and nature. The pathological specimens can be used to teach clinicians and pathologists about the rarest diseases of ancient times. In fact, they are priceless components of any pathology department. Recent development in museum field has led to the emergence of newer innovative methods of preservation and demonstration of specimens. 


\section{References}

1. Museum definition- Available at http://icom.museum/the-vision/museumdefinition/. Accessed on 3rd November 2020.

2. Museum Techniques- A Review; R J V Pulvertaft- Journal of clinical Pathology 1950;3, 1.

3. Museum Techniques- $A$ Review; $R \quad J \quad V$ Pulvertaft- Journal of clinical Pathology 1950;3

4. . Arzu Cilasun Kunduraci, Virtual Museum and Review of Virtual Museums in Turkey; May 2012 Conference: 5T A New Affair: Design History and Digital Design Museum At: Izmir. Vol: 7

5. Shankargouda Patil et al, The Museum Maze in Oral Pathology Demystified Part I- The Journal of Contemporary Dental Practice, July-Aug 2013;14(4): pg 770-776.

6. Rao RS, Premalatha BR. Grossing in oral pathology- general principles and guidelines. World J Dent 2010;1(1): pg 35-41.
7. Srinivasan $M$, Sedmak $D$, Jewell S. Effect of fixatives and tissue processing on the content and integrity of nucleic acids. Am J Pathol 2002;161: pg 1961-1971

8. Frank Oppenheimer. Rationale for a science museum. Curator: The Museum Journal 1968;1(3): pg 206-209.

9. Natarajan S, Ranjan J, Boaz K. Museum mounting techniques: revisited economode. Indian J Pathol Microbiol 2012;55: pg 260-261.

10. Culling CFA, Allison RT. Handbook of Histopathological and Histochemical Techniques $3^{\text {rd }}$ ed. WT Barr Butterworth and Co Ltd 1974: pg 537-541.

11. Shankargouda Patil et al, The Museum Maze in Oral Pathology Demystified Part II- The Journal of Contemporary Dental Practice, Sep- Oct 2013;14(5): pg 987-992 